\title{
Present and future status of artisanal fisheries in the Adriatic Sea (western Mediterranean Sea)
}

\author{
Pranovi Fabio*, Colla Silvia, Valeri Paolo, Marco Anelli Monti \\ Environmental Sciences, Informatics and Statistics Dept., University Ca' Foscari of Venice, Via Torino 155, 30170 Venice, Italy
}

\section{A R T I C L E I N F O}

\section{Article history:}

Received 26 August 2015

Received in revised form

7 January 2016

Accepted 13 January 2016

Available online $\mathrm{xxx}$

\section{Keywords:}

Artisanal fisheries

CPUE

Discard ratio

Primary production required

L-index

Adriatic Sea

\begin{abstract}
A B S T R A C T
Artisanal fisheries represents an important source of employment and income for many Mediterranean coastal communities, as well as an important cultural and traditional identity factor at a regional level. However, despite its importance, it is generally under-studied, in both ecological and socio-economic terms, so hampering the chance of developing sustainable and integrated management measures. At present, on the West coast of the Adriatic Sea, within the three-mile area, artisanal fisheries and hydraulic dredging are the only approved commercial fishing activities. This study confirmed the importance of the artisanal fisheries in this area, representing a multitarget and multigear activity. Despite the 39 exploited species, however, we found high vulnerability both for species ( $76 \%$ of total catches depend upon only three species-cuttlefish, mantis shrimp, and sole) and thermal affinity groups (cold and temperate species contributed to the entire catches). Furthermore, our data showed that fishing effort and CPUE values were greater than those reported at the regional level, and also indicated that the discard rate was lower than in other Adriatic areas. Regarding ecological effects, the two trophodynamic indicators that we applied showed a sustainable situation, but scenarios of possible changes in environmental or fishing effort conditions highlighted the proximity of the stock to the unsustainability threshold. Our findings suggest the need for an adequate management strategy to cope with possible future changes in population boundaries and conditions.
\end{abstract}

๑) 2016 Elsevier Ltd. All rights reserved.

\section{Introduction}

Artisanal and small-scale fisheries are often equated (see FAO glossary), because they share common features, such as low capital investment, ownership by fishermen, and the exploitation of coastal fishing grounds located within a few hours' travel from the port (Colloca et al., 2004). Generally, artisanal activities can be characterized by the relative level of technology (or "artisanality") and by whether they are multitarget and multigear, as seasonal changes in fishing techniques are implemented to maximize catches and, therefore, profitability (Farrugio et al., 1993; Battaglia et al., 2010; Forcada et al., 2010). Despite these common features, artisanal fisheries tend to be highly heterogeneous in space, and strictly depend upon local environmental and socio-economic conditions (Stergiou et al., 2006; Guyader et al., 2013). Typically, these activities are deeply rooted in coastal populations, and play crucial socio-economic roles in both developing and developed

\footnotetext{
* Corresponding author.

E-mail address: fpranovi@unive.it (P. Fabio).
}

countries, including those along European coastal zones. These factors may be magnified in the Mediterranean basin, where the multispecificity of catches and dispersion of fleets across a high number of small ports are the main features of all of its fisheries. Such characteristics could represent major reasons why the artisanal fisheries in the Mediterranean Sea and Europe are generally not well characterized (Battaglia et al., 2010; Guyader et al., 2013).

Small scale and artisanal fisheries are often attributed with the potential to contribute to food security, economic growth, the development of coastal areas, and the preservation of marine ecosystems (FAO, 2005; Garcia et al., 2008). However, limited data are available at the regional level regarding production or the socioeconomic and ecological implications, which substantially limit opportunities to produce a real assessment of such issues and generate effective management strategies.

Within this context, the Italian situation may represent an interesting case study. Since June 2010, the implementation of Council Regulation (EC) no. 1967/2006 introduced a ban of trawling activities within three nautical miles of the coast or within the $50 \mathrm{~m}$ isobaths where this was closer to the shoreline. As a consequence, 
artisanal fishing remained almost the only exploitative activity within the coastal area. For example, on the West coast of the Adriatic Sea within the three-mile area, artisanal fisheries and hydraulic dredging for striped venus clams (Chamelea gallina) are the only permitted activities (Pranovi et al., 2015). Nevertheless, very few studies have been carried out to characterize the possible ecological effects and management strategies that result from this regulation (Fabi and Grati, 2005; De Mauro et al., 2007).

To begin to address this issue, this present study aims to assess the following criteria:

(1) the basic features of artisanal fisheries along the Venetian coast, in terms of fishing strategies and catches;

(2) the potential vulnerability of artisanal fisheries, also in relation to the potential effects of climate change; and

(3) the sustainability of exploitative activities, also considering the expected modifications of fishing effort and/or environmental features.

\section{Materials and methods}

\subsection{Study area}

The Northern Adriatic Sea includes all of the critical elements attributed to a 'typical' coastal area, such as the concentration of many economic activities and the presence of different types of anthropogenic pressures, including important fisheries, aquaculture activities (mussel farms), widely distributed seaside tourism, and extended seaport activities. Furthermore, the provision of many goods and services, including renewable resources, are particularly critical in the trade-off between ecological status and the impacts of exploitation. Additionally, this area is particularly exposed to the effects of climate change because of its local geographic features. Indeed, the zone has been described as an area where Mediterranean climatic conditions are replaced by boreal conditions, supporting the presence of 'glacial relicts' and representing a type of 'cul de sac' for some species (Ben Rais Lasram et al., 2010; Libralato et al., 2015).

The study area is located on the West coast of the Northern Adriatic Sea, between Caorle and Cavallino-Treporti (Fig. 1). It is a flat coastal area characterized by the presence of sandy beaches, transitional water systems (laguna di Caorle e laguna del Mort) and river mouths (Tagliamento and Sile), which results in high habitat diversity. Caorle and Jesolo represent the two most important ports in this area, and they are the home to the major fishing fleets of the region apart from Chioggia, which is the largest port in the entire basin.

\subsection{Fleet characteristics and sampling activities}

This study was focused on two main fleets (Jesolo and Caorle) located along the northern part of the Venetian coast (Fig. 1). A preliminary description of these fleets was performed based on the EU Fleet Register (number of vessels and licences) and local fishermen's cooperatives (number of fishermen per vessel and days at sea). These data were subsequently validated by interviewing fishermen and performing direct observations at the quay.

Descriptions of catches, both in qualitative and quantitative terms, were performed by onboard observations that were carried out bi-monthly on four vessels (two per fleet) from January to December 2014. According to the sampling protocol, each individual organism that was caught was classified at the species level and weighed (grams of wet weight); in cases of uncertain classification, samples were collected and successively identified in the laboratory. All catches were divided into target species, by-catch, and discarded organisms (both commercial and non-commercial species). Data were integrated with weekly observations on the quay in which the same vessels were followed.

\subsection{Data analysis}

Based on the collected data, the catch per unit of effort (CPUE) for each gear and species was estimated in terms of biomass per day per vessel $\left(\mathrm{kg} \mathrm{v}^{-1} \mathrm{~d}^{-1}\right)$. To assess the total catches per year at the fleet level, the following criteria were used: CPUE data, number of days at sea, and number of artisanal fisheries vessels in the area. For the number of days at sea, two different estimates were used: 150 days, which was based on the official statistical data from 2012, to 214 days, which was based on observations from 2014 carried out during this present study. The bootstrapping method was applied to estimate the 95\% confidence interval (Shao and Tu, 1996; Lehtonen and Pahkinen, 2004). According to the procedure, CPUE samples were randomly drawn from the database, repeating the process for 1000 times. Once built, the new dataset (composed by all targeted species) was used to estimate the confidence interval $(\alpha=0.05)$.

To investigate the sustainability of artisanal fisheries and their associated ecological effects, the Primary Production Required (PPR) to sustain the fishery (Pauly and Christensen, 1995) and Lindex (Libralato et al., 2008) were estimated.

The PPR enabled the quantification of fishing pressures on the ecosystem, as it calculated the amount of energy exported from the system by landings. It is usually standardized as a percentage of the annual Primary Production of the area, and can be calculated as follows,

$P P R=\sum_{i=1}^{n} \frac{L_{i}}{C R}\left(\frac{1}{T E}\right)^{\left(T L_{i}-1\right)}$

with $\mathrm{L}_{\mathrm{i}}=$ landing of $i$-species; $\mathrm{CR}=$ conversion rate of wet weightto-carbon (fixed at 1:9, according to Pauly and Christensen, 1995); $\mathrm{TE}=$ transfer efficiency (fixed at $10.5 \%$, according to Libralato et al., 2015); TL = trophic level of $i$-species (assigned according to Pranovi et al., 2014).

Primary production for the NAS was estimated by using monthly chlorophyll-a data derived from the MODIS satellite (http://neo.sci. gsfc.nasa.gov/), according to Behrenfeld and Falkowski (1997).

The L-index is a synthetic index that takes into account both ecosystem properties (primary production and transfer efficiency) and features of fishing activities (trophic levels of catches and PPR). This index allows for estimates about how the effects of energy extracted from the system by exploitative activities can be propagated through the trophic chain.

The L-index is defined as,

Lindex $=\frac{P P R T E^{T L_{c}-1}}{P P \ln (T E)}$

where PPR = Primary Production Required (see above); $\mathrm{TE}=$ transfer efficiency (fixed at $10.5 \%$, according to Libralato et al., 2015) TLc = the mean trophic level of catches; PP = Primary Production (see above).

The method allows also for estimates of the probability that such energy loss is sustainable based on a non-linear empirical relationship between the L-index and the probability to be sustainably exploited (psust) for an ecosystem (Libralato et al., 2008).

To simulate the possible effects of changes in both social and environmental conditions, the PPR\% and L-index indicators were 


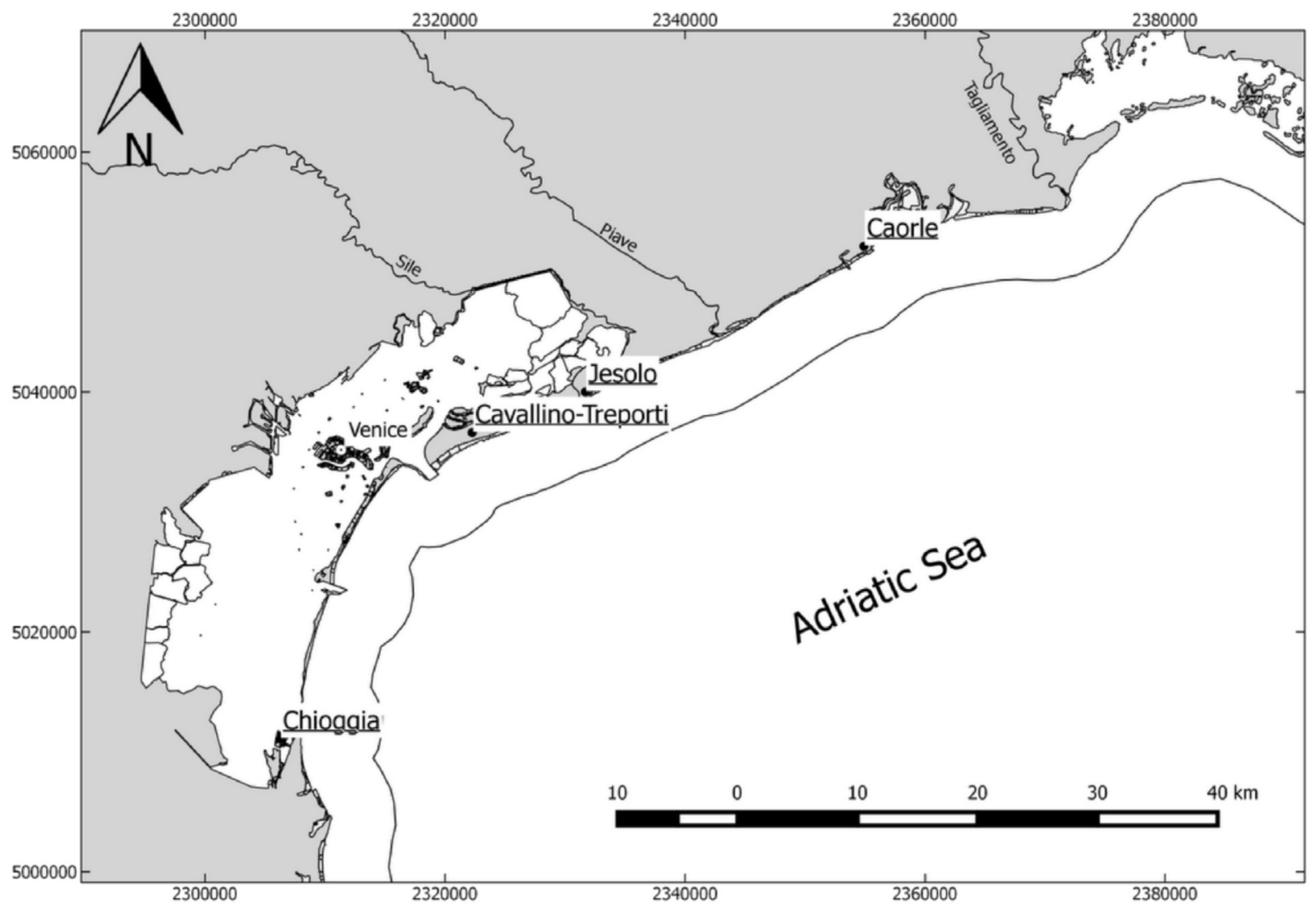

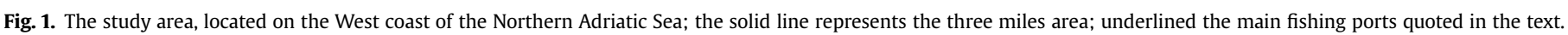

applied to three different scenarios, in which the recent trends recorded in the Northern Adriatic were taken into account:

a) an increase of the fishing effort, resulting from reconversion of fishermen from small trawling to the artisanal fisheries, based on recent findings in the area as a response to the implementation of new management strategies (Pranovi et al., 2015);

b) a reduction of the primary production (PP) in the Northern Adriatic Sea, as consequence of a tendency towards oligotrophy, which was recently described by Giani et al. (2012);

c) a combination of ' $a$ ' and ' $b$ ', i.e. increased fishing effort and reduced $P P$.

Finally, to investigate the vulnerability of artisanal fisheries to the potential effects of climate changes, the composition of catches based on thermal affinity groups (Pranovi et al., 2013) were analysed. In this approach, each species was categorised based on the mean distribution area in terms of latitudinal range: species with a distribution over $45^{\circ} \mathrm{N}$, species within the $30^{\circ} \mathrm{N}-45^{\circ} \mathrm{N}$ range, and species mainly found below $30^{\circ} \mathrm{N}$. These categories allowed for the identification of three climatic affinity groups-cold, temperate, and warm. Thresholds of $30^{\circ}$ and $45^{\circ}$ were arbitrarily selected with $30^{\circ} \mathrm{N}$ representing the southern limit of the Mediterranean basin and $45^{\circ} \mathrm{N}$ representing its northern limit, excluding the northernmost regions of the Adriatic and Black Sea (Pranovi et al., 2013).

\section{Results}

\subsection{The fleet and fishing techniques}

According to the EU Fleet Register, the fleet in the study area included 216 vessels, among which 79 belonged to an artisanal fisheries, as confirmed by quay observations. The features of this component of the fleet can be summarized as follows: length, 4.30-12.08 m; gross tonnage, 1-2 tons; and crew, 1-2 fishermen. These vessels mainly operate in fishing grounds located between 0.1 and 3 miles from the coastline.

The collected data indicated that artisanal fishermen adopt four different fishing techniques-gill nets, trammel nets, pots, and basket traps - that vary seasonally (Table 1 ).

Gillnets are employed from May to June and from September to November, and these target sole (Solea solea), mantis shrimp (Squilla mantis), and tub gurnard (Chelidonichthys lucerna) (Table 1). The net length ranges between 1.000 and $5.000 \mathrm{~m}$, and the length used mainly depends upon the vessel size. Catches can include up to 78 species ( 8 target, 27 by-catch, and 43 discarded species, reflecting $78.5 \%, 13.3 \%$, and $8.2 \%$ of the total biomass, respectively). Notably, sole, mantis shrimp, and smooth-hound shark (Mustelus mustelus) represented $73 \%$ of the commercial biomass (Table 2 and S1). The resulting discarded fraction is dominated by three species-spined murex (Bolinus brandaris), grey swimming crab (Liocarcinus vernalis), and common eagle ray (Myliobatis aquila) (Table S1). Regarding the total CPUE, gill nets represent the second most common fishing technique (Fig. 2) and the most important species yielded are sole $\left(15.0 \mathrm{~kg} \mathrm{~d}^{-1} \mathrm{v}^{-1}\right)$, smooth-hound shark (7.1 $\mathrm{kg} \mathrm{d}^{-1} \mathrm{v}^{-1}$ ) and mantis shrimp (4.3 $\mathrm{kg} \mathrm{d}^{-1} \mathrm{v}^{-1}$; Table S2).

Trammel nets are employed in the periods from January to March and November to December, and they target flatfish - turbot (Scophthalmus maximus), brill (Scophthalmus rhombus), European flounder (Platichthys flesus) - and cuttlefish (Sepia officinalis) (Table 1 and S2). The net length is between 350 and $2000 \mathrm{~m}$, and mainly depends upon the vessel size. Catches can include up to 37 
Table 1

Description of the artisanal fishery, in terms of gears, number of vessels, main target species and fishing season.

\begin{tabular}{|c|c|c|c|}
\hline Fishing technique & No. vessels & Target species & Fishing season \\
\hline Gillnets & 79 & Sole, mantis shrimp and tub gurnard & May-Jun, Sep-Nov \\
\hline Trammel nets & 79 & Flatfish & Jan-Mar, Nov-Dec \\
\hline Pots & 79 & Cuttlefish & Apr-Jul \\
\hline Basket traps & 75 & Mantis shrimp & Jul-Oct \\
\hline
\end{tabular}

Table 2

Description of artisanal fishery catches, in terms of incidence (\%) on the total catch of target species, by-catch and discard, per fishing gear.

\begin{tabular}{lllc}
\hline Fishing technique & Target & By-catch & Discard \\
\hline Trammel nets & 73.8 & 23.1 & 3.1 \\
Gillnets & 78.5 & 13.3 & 8.2 \\
Pots & 99.6 & 0 & 0.4 \\
Basket traps & 86.0 & 0 & 14.0 \\
\hline
\end{tabular}

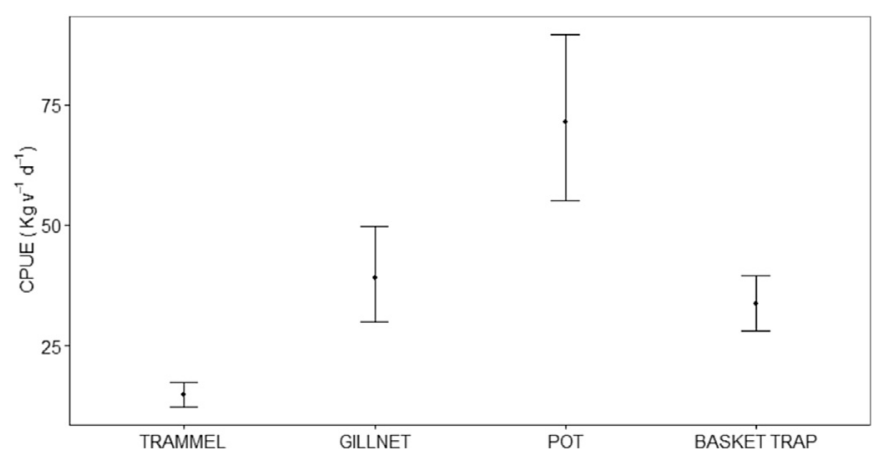

Fig. 2. Comparison among the different fishing gear in terms of Catch per Unit of Effort $\left(\mathrm{kg} \mathrm{v}^{-1} \mathrm{~d}^{-1}\right)$; mean and 95\% interval confidence.

species ( 5 target, 21 by-catch, and 11 discarded species, reflecting $74 \%, 23 \%$ and $3 \%$ of the total biomass, respectively) (Table 2 and 51 ), among which turbot, cuttlefish, and brill represent $62 \%$ of the commercial biomass. The discarded fraction is almost entirely composed of three species-grey swimming crab (Liocarcinus vernalis), twait shad (Alosa fallax), and spined murex (Bolinus brandalis) (Table S1). In terms of the total CPUE, trammel nets represent the fourth most common fishing technique (Fig. 2), and the most important species that it yields are turbot $\left(4.5 \mathrm{~kg} \mathrm{~d}^{-1} \mathrm{v}^{-1}\right)$, cuttlefish $\left(2.5 \mathrm{~kg} \mathrm{~d}^{-1} \mathrm{v}^{-1}\right)$, and brill $\left(2.1 \mathrm{~kg} \mathrm{~d}^{-1} \mathrm{v}^{-1}\right)$ (Table S2).

Pots are employed from April to the beginning of July, and they target cuttlefish. This activity is regulated by the Port Authority, which establishes annual monitoring of the fishing season and monitors fishing vessels. In 2014, the fishing period was from April to 10 July with an allowance of 300 pots per fisherman (in cases of three or more embarked fishermen, the maximum limit of pots was 600 per vessel). Catches are composed of $99.6 \%$ target species, with a few grey swimming crabs being the discarded species. In terms of the total CPUE, pots represent the best fishing technique (Fig. 2), with $71.4 \mathrm{~kg} \mathrm{~d}^{-1} \mathrm{v}^{-1}$ of cuttlefish (Table S1).

Basket traps are employed from July to October and they target mantis shrimp. Catches are composed of $86 \%$ target species. The discarded fraction represents four species of invertebrates-spined murex, banded dye-murex (Hexaplex trunculus), sea snail (Nassarius mutabilis), and netted dog whelk (Nassarius nitidus). In terms of the total CPUE, basket traps represent the third best fishing technique (Fig. 2), with $33.9 \mathrm{~kg} \mathrm{~d}^{-1} \mathrm{v}^{-1}$ of mantis shrimp (Table S1).

Based on the CPUE data and vessel numbers for each fishing technique, an annual catch of 735 or 1050 tons is estimated
(Table 3) for different fishing effort estimates of 150 or 214 days at sea, respectively. Cuttlefish, mantis shrimp, sole, and turbot showed the highest values, ranging from 58 to 440 tons per year (Table 3).

\subsection{Ecological effects}

While the mean trophic level of catches remained stable (3.29), the Primary Production Required to sustain catches (PPR\%) for the entire fleet ranged from $10 \%$ to $14 \%$ (Table 4 ), depending on the fishing effort estimate, which was either 150 or 241 fishing days. The L-index and the relative probability to be sustainably fished showed a similar pattern (Table 4).

For the scenario of a potential 50\% increase of the fishing effort (in terms of the vessels number) in the area as a result of fishermen reconversion (see M\&M), the PPR\% slightly increased and the probability of sustainable fishing is reduced to $61 \%$ or $49 \%$ for 150 or 241 fishing days, respectively (Table 4). A similar trend has been recorded taking into account a possible reduction in primary production, with a reduction of the probability of sustainable fishing (Table 4).

Finally, combining the two scenarios by increasing the fishing effort and decreasing the primary production resulted in an increase of the ecological effects, with PPR\% values that ranged between $19 \%$ and $24 \%$, and the probability to be sustainably fished (psust) decreasing around of far below the 50\% threshold (Table 4).

In order to analyse the contribute of each fishing gear, the PPR (\%) and the probability of sustainable fishing are estimated under the four scenarios, considering an increase of the fishing effort ranging from 10 to $100 \%$. The observed pattern is similar for all the tested scenarios. In terms of PPR (\%) the highest values are recorded for the pot (5-17\%), whereas the lowest were referred to the basket traps (<2.5\%) (Fig. 3). With reference to the probability of sustainable fishing, values remained over than $70 \%$, with the lowest recorded for the gillnet (Fig. 4).

\subsection{Climate change vulnerability}

Regarding the potential vulnerability to climate change effects, an analysis of the catch composition based on thermal affinity groups revealed that the cold and temperate affinity species represent the two main caught groups, accounting on average for $64 \%$ and $31 \%$ of the total catch, respectively (Table 5). A similar pattern also resulted from analyses of catches in relation to different fishing techniques, with the exception of the basket traps, in which the catch is composed only of temperate species, because the mantis shrimp belongs to this affinity group (Table 5).

\section{Discussion}

Similar to other regions throughout the world, the artisanal or small scale fisheries in the Mediterranean Sea is recognised as a fundamental factor for the cultural and traditional identity of the region, and also represents an important source of employment and income for coastal communities (Farrugio et al., 1993; AdriaMed, 2005). Nevertheless, artisanal fisheries have been scarcely managed or studied (Guyader et al., 2013). For example, 
Table 3

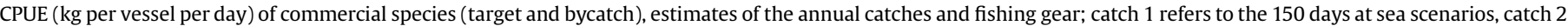

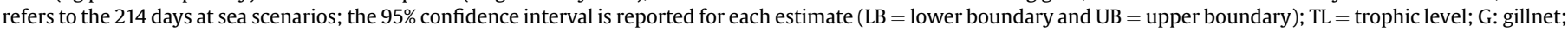
T: trammel net; P: pot; B: basket trap.

\begin{tabular}{|c|c|c|c|c|c|c|c|c|c|c|c|c|}
\hline Species & & $\mathrm{TL}$ & LB & CPUE $\left(\mathrm{kg} \mathrm{v}^{-1} \mathrm{~d}^{-1}\right)$ & UB & LB & Total catches 1 (tonnes) & UB & LB & Total catches 2 (tonnes) & UB & gear \\
\hline Common cuttlefish & Sepia officinalis & 3.60 & 55.5 & 74.3 & 95.3 & 233.6 & 311.5 & 398.8 & 333.3 & 444.4 & 568.9 & $P-T-G$ \\
\hline Mantis shrimp & Squilla mantis & 2.60 & 59.1 & 72.1 & 87.3 & 151.1 & 190.3 & 240.3 & 215.5 & 271.6 & 342.8 & $B-G$ \\
\hline Common sole & Solea solea & 3.13 & 11.2 & 15.7 & 21.1 & 62.0 & 86.1 & 114.8 & 88.5 & 122.8 & 163.8 & $G-T$ \\
\hline Smooth-hound shark & Mustelus mustelus & 3.83 & 3.5 & 7.6 & 12.3 & 19.3 & 41.2 & 65.8 & 27.6 & 58.8 & 93.9 & $G-T$ \\
\hline Turbot & Psetta maxima & 3.96 & 3.1 & 4.6 & 6.2 & 11.2 & 16.7 & 22.4 & 15.9 & 23.8 & 32.0 & $T$ \\
\hline Tub gurnard & Chelidonichthys lucerna & 3.65 & 2.3 & 3.3 & 4.5 & 11.6 & 17.1 & 23.4 & 16.5 & 24.3 & 33.3 & $G-T$ \\
\hline Brill & Scophthalmus rhombus & 3.96 & 1.8 & 2.6 & 3.5 & 6.9 & 10.4 & 14.0 & 9.9 & 14.8 & 20.0 & $T-G$ \\
\hline Gilthead seabream & Sparus aurata & 3.26 & 1.1 & 2.6 & 4.3 & 6.2 & 13.8 & 22.9 & 8.8 & 19.7 & 32.6 & $T-G$ \\
\hline Sand steenbras & Lithognathus mormyrus & 3.42 & 0.6 & 1.8 & 3.3 & 3.4 & 10.0 & 18.2 & 4.8 & 14.2 & 25.9 & $T-G$ \\
\hline Mediterranean scaldfish & Arnoglossus laterna & 3.59 & 0.7 & 1.7 & 3.0 & 3.7 & 9.3 & 16.6 & 5.3 & 13.3 & 23.6 & $G$ \\
\hline Shi drum & Umbrina cirrosa & 3.46 & 0.6 & 1.4 & 2.3 & 3.1 & 6.7 & 10.8 & 4.5 & 9.6 & 15.4 & $T-G$ \\
\hline European seabass & Dicentrarchus labrax & 3.80 & 0.3 & 1.1 & 2.2 & 1.2 & 4.2 & 8.4 & 1.7 & 6.0 & 12.0 & $T-G$ \\
\hline European flounder & Platichthys flesus & 3.19 & 0.3 & 1.1 & 2.1 & 1.2 & 3.8 & 7.6 & 1.7 & 5.4 & 10.8 & $T-G$ \\
\hline Spiny dye-murex & Bolinus brandaris & 3.25 & 0.3 & 0.7 & 1.1 & 1.9 & 3.9 & 6.3 & 2.8 & 5.6 & 9.0 & $T$ \\
\hline Golden grey mullet & Liza aurata & 2.76 & 0.1 & 0.6 & 1.5 & 0.4 & 2.7 & 6.2 & 0.6 & 3.9 & 8.9 & $G$ \\
\hline European lobster & Homarus gammarus & 2.60 & 0.0 & 0.3 & 0.9 & 0.0 & 1.6 & 4.4 & 0.0 & 2.2 & 6.3 & $G$ \\
\hline Thinlip grey mullet & Liza ramada & 2.76 & 0.0 & 0.3 & 0.6 & 0.2 & 1.2 & 2.7 & 0.3 & 1.7 & 3.9 & $G$ \\
\hline Brown ray & Raja miraletus & 3.76 & 0.1 & 0.1 & 0.2 & 0.4 & 0.7 & 1.1 & 0.5 & 1.0 & 1.5 & $G-T$ \\
\hline Leaping mullet & Liza saliens & 2.76 & 0.0 & 0.1 & 0.2 & 0.2 & 0.5 & 1.0 & 0.2 & 0.8 & 1.5 & $G$ \\
\hline Caramote prawn & Penaeus kerathurus & 2.70 & 0.0 & 0.1 & 0.2 & 0.3 & 0.5 & 0.9 & 0.4 & 0.8 & 1.3 & $G$ \\
\hline Bluefish & Pomatomus saltatrix & 4.50 & 0.0 & 0.1 & 0.2 & 0.0 & 0.3 & 0.9 & 0.0 & 0.5 & 1.2 & $T$ \\
\hline Nursehound & Scyliorhinus stellaris & 3.69 & 0.0 & 0.1 & 0.3 & 0.0 & 0.5 & 1.4 & 0.0 & 0.7 & 2.0 & $T-G$ \\
\hline Red scorpionfish & Scorpaena scrofa & 4.11 & 0.0 & 0.1 & 0.2 & 0.0 & 0.4 & 1.3 & 0.0 & 0.6 & 1.9 & $T-G$ \\
\hline Atlantic horse mackerel & Trachurus trachurus & 3.59 & 0.0 & 0.1 & 0.1 & 0.2 & 0.4 & 0.7 & 0.2 & 0.6 & 1.1 & $T-G$ \\
\hline Brown meagre & Sciaena umbra & 3.70 & 0.0 & 0.1 & 0.2 & 0.0 & 0.4 & 1.0 & 0.0 & 0.5 & 1.4 & $T-G$ \\
\hline Annular seabream & Diplodus annularis & 3.50 & 0.0 & 0.1 & 0.2 & 0.0 & 0.3 & 0.7 & 0.0 & 0.4 & 1.1 & $G-T$ \\
\hline Leerfish & Lichia amia & 4.50 & & $<0.1$ & & 0.0 & 0.2 & 0.6 & 0.0 & 0.3 & 0.8 & $T-G$ \\
\hline Common octopus & Octopus vulgaris & 4.10 & & $<0.1$ & & 0.0 & 0.1 & 0.5 & 0.0 & 0.2 & 0.7 & $T$ \\
\hline White seabream & Diplodus sargus & 3.04 & & $<0.1$ & & 0.0 & 0.1 & 0.4 & 0.0 & 0.2 & 0.5 & $G-T$ \\
\hline Common pandora & Pagellus erythrinus & 3.48 & & $<0.1$ & & 0.0 & 0.2 & 0.5 & 0.0 & 0.2 & 0.7 & $G$ \\
\hline Atlantic mackerel & Scomber scombrus & 3.65 & & $<0.1$ & & 0.0 & 0.1 & 0.2 & 0.0 & 0.1 & 0.3 & $G$ \\
\hline John dory & Zeus faber & 4.5 & & $<0.1$ & & 0.0 & 0.1 & 0.1 & 0.0 & 0.1 & 0.2 & $G$ \\
\hline Thicklip grey mullat & Chelon labrosus & 2.42 & & $<0.1$ & & 0.0 & 0.1 & 0.2 & 0.0 & 0.1 & 0.3 & $T$ \\
\hline European squid & Loligo vulgaris & 3.20 & & $<0.1$ & & 0.0 & 0.1 & 0.2 & 0.0 & 0.1 & 0.2 & $T$ \\
\hline Whiting & Merlangius merlangus & 4.37 & & $<0.1$ & & 0.0 & 0.1 & 0.2 & 0.0 & 0.1 & 0.2 & $G$ \\
\hline Great scallop & Pecten jacobaeus & 2.39 & & $<0.1$ & & & $<0.1$ & & & $<0.1$ & & $G$ \\
\hline Red mullet & Mullus barbatus & 3.15 & & $<0.1$ & & & $<0.1$ & & & $<0.1$ & & $G-T$ \\
\hline Spotted weever & Trachinus araneus & 4.18 & & $<0.1$ & & & $<0.1$ & & & $<0.1$ & & $G$ \\
\hline Salema & Sarpa salpa & 2.00 & & $<0.1$ & & & $<0.1$ & & & $<0.1$ & & $B$ \\
\hline
\end{tabular}

Table 4

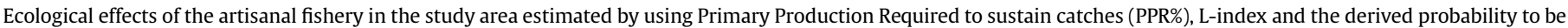
sustainably fished (psust), considering both commercial and discard fraction for all the fishing techniques combined; for description of the scenarios see the main text.

\begin{tabular}{|c|c|c|c|c|c|c|c|c|}
\hline & \multicolumn{2}{|c|}{ Present situation } & \multicolumn{2}{|c|}{ Increased fishing effort } & \multicolumn{2}{|c|}{$\begin{array}{l}\text { PP reduction (present fishing } \\
\text { effort) }\end{array}$} & \multicolumn{2}{|c|}{$\begin{array}{l}\text { PP reduction (increased } \\
\text { fishing effort) }\end{array}$} \\
\hline & 150 days & 214 days & 150 days & 214 days & 150 days & 214 days & 150 days & 214 days \\
\hline PPR\% & 10.2 & 14.5 & 15.2 & 21.8 & 12.7 & 18.1 & 19.1 & 24.2 \\
\hline Lindex & 0.025 & 0.036 & 0.037 & 0.054 & 0.033 & 0.045 & 0.048 & 0.068 \\
\hline psust & 0.71 & 0.61 & 0.61 & 0.49 & 0.63 & 0.55 & 0.53 & 0.29 \\
\hline
\end{tabular}

the large heterogeneity and variability of artisanal fisheries among different areas has presented an important obstacle to the development of standardized data collection routines that are based in many harbours and small ports (Colloca et al., 2004).

The importance of this role has recently increased, at least along the Italian coasts, in relation to the introduction of bans for trawling activities within three miles of the coastline. Consequently, in the western region of the Adriatic Sea artisanal fisheries have remained along with hydraulic dredging, which represent the only ongoing commercial fishing activities (Pranovi et al., 2015). Within this context, it is necessary to increase our knowledge and monitoring of these activities to best implement effective management strategies.

Given the difficulty involved in monitoring artisanal fisheries landings, as fishermen sell a large portion of their catch outside of the fish market in areas that are often difficult to reach and/or are far from the landing port, an on-board and on-quay data collection system has been implemented.

Our findings confirmed that the artisanal fishing is a multitarget and multigear activity, as has been described for other Adriatic (AdriaMed, 2005; Fabi and Grati, 2005; Matić-Skoko et al., 2011), Mediterranean (Stergiou et al., 2006; Tzanatos et al., 2005; Forcada et al., 2010) and European areas (Guyader et al., 2013). Although features of the fleet (on average, $1.5 \mathrm{t}$ of GT and 1.5 crew members) were aligned with those reported for the region (MIPAAF, 2014) and other European ports (Guyader et al., 2013), our estimates of fishing effort were higher than that of official Italian statistics (89 days at sea for 2012). Our estimates, which ranged between 150 and 214 


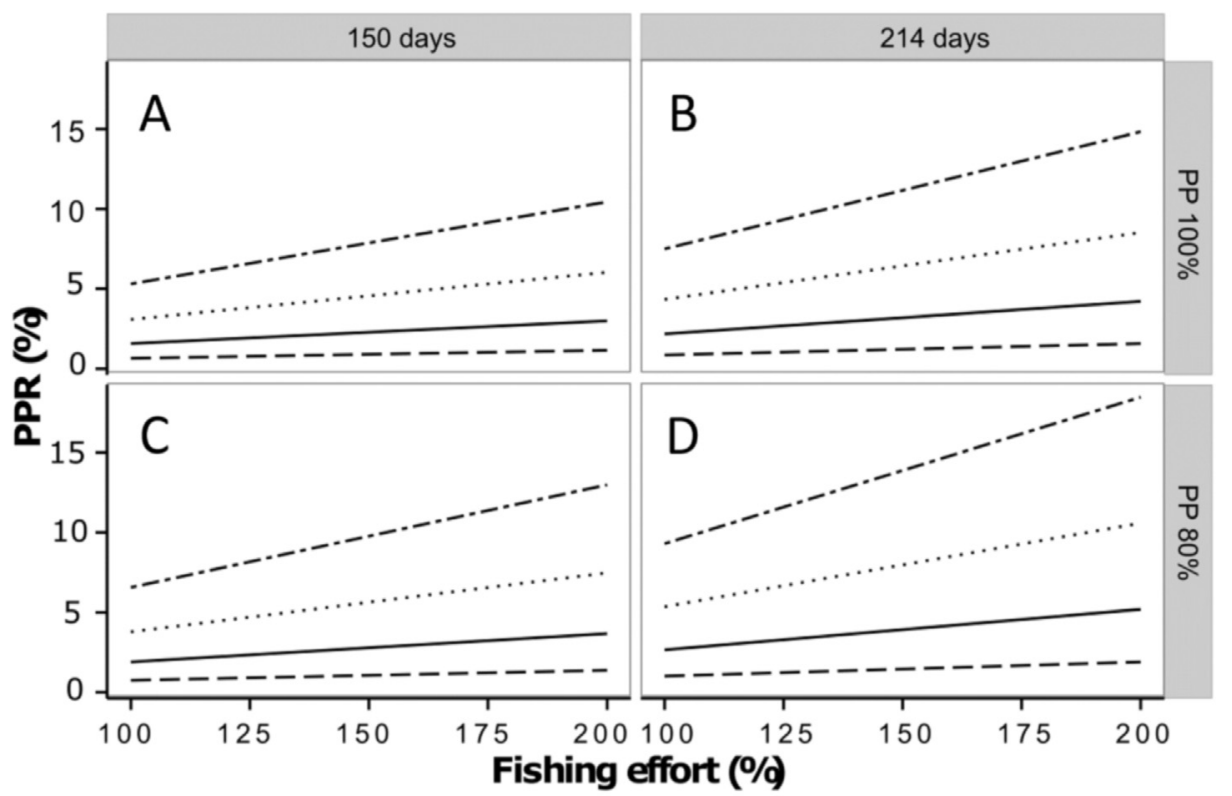

— trammel $\cdots \cdot$ gillnet -- basket $\cdot-\cdot \cdot$ pot

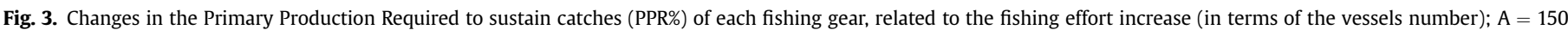

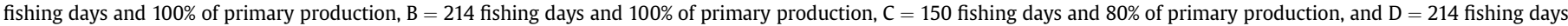
and $80 \%$ of primary production.

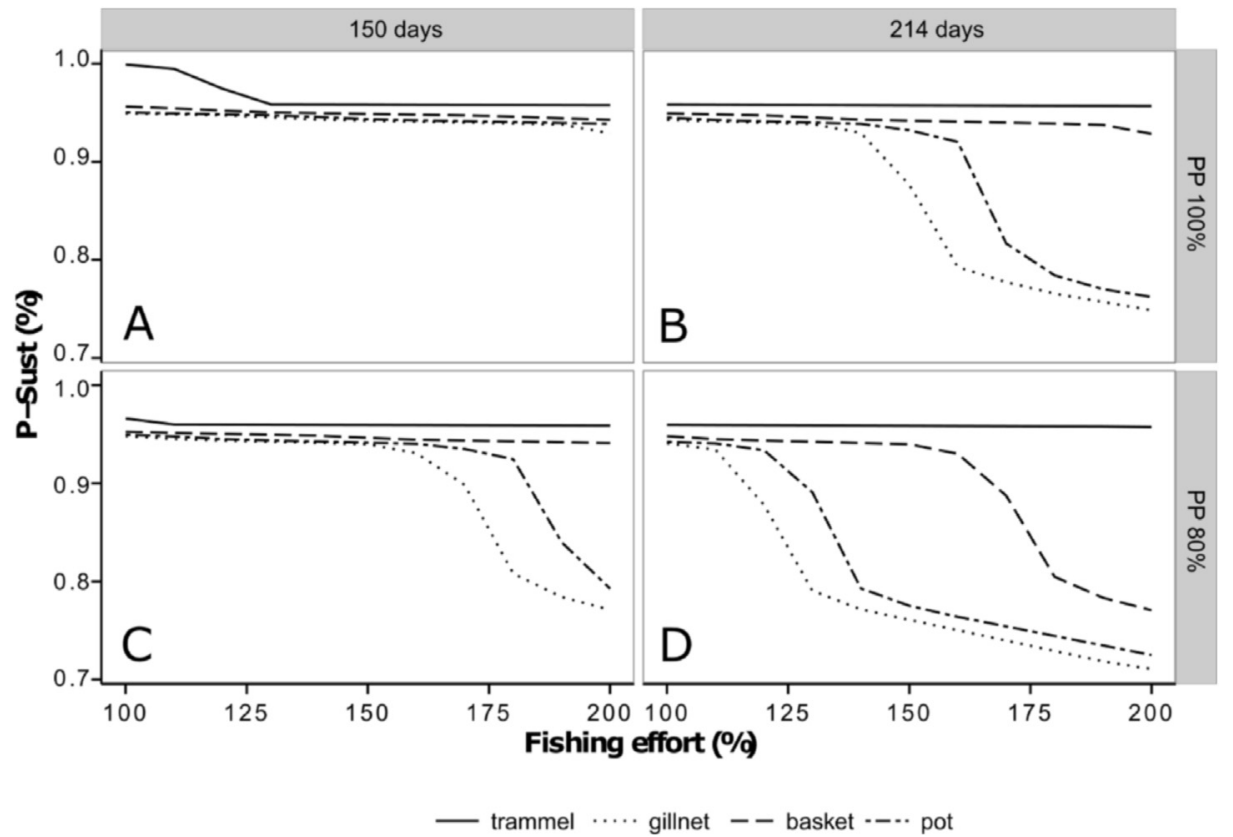

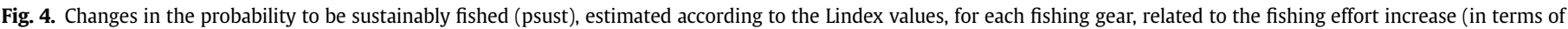

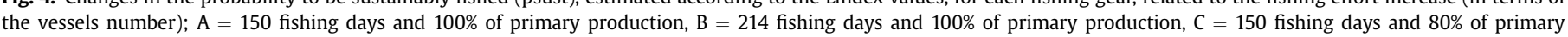
production, and $\mathrm{D}=214$ fishing days and $80 \%$ of primary production.

days at sea per year, fell within the upper part of the range reported for various fisheries throughout Europe (Guyader et al., 2013). Finally, as reported for other European fisheries (Guyader et al., 2013), our collected data indicated a high amount of vulnerability as even though 39 target species were targeted, $76 \%$ of total catches depended upon only three species-cuttlefish, mantis shrimp, and sole. This partially occurs because, within the context of polyvalence, fishermen seasonally employ two types of fishing gear-pots and basket traps, which results in nearly monospecific (for cuttlefish and mantis shrimp) exploitation in coastal waters of these temporary resources. These patterns are in contrast with the common idea that artisanal fishing, is a highly dynamic activity that can switch metiers depends upon the abundance of target species and dynamic environmental conditions, so it can therefore be 
Table 5

Catch composition in terms of incidence (\%) on total catch of thermal affinity groups (cold, temperate, warm and ubiquitous species) for each fishing gear and all of them combined (total catches).

\begin{tabular}{lccll}
\hline & Cold & Temperate & Warm & Ubiquitous \\
\hline Trammel nets & 81.7 & 9.1 & 3.2 & 6.0 \\
Gillnets & 57.0 & 31.6 & 3.5 & 7.9 \\
Pots & 100 & 0 & 0 & 0 \\
Basket traps & 0 & 100 & 0 & 0 \\
Total catches & 64.0 & 31.1 & 0.9 & 4.0 \\
\hline
\end{tabular}

considered a highly resilient activity (Colloca et al., 2004; Tzanatos et al., 2005; García-Rodríguez et al., 2006).

Within this context, the potential vulnerability to thermal changes must also be considered because of the species composition in terms of thermal affinity groups. Cold and temperate species contribute to all catches, exposing these fisheries to negative effects resulting from expected modifications of nekton assemblages (Fortibuoni et al., 2015; Libralato et al., 2015). For example, the northern Adriatic Sea can be considered to be a particularly vulnerable area that hosts several species that are adapted to boreal climatic conditions and is configured as a cul-de-sac that prevents the northward migration of species (Ben Rais Lasram et al., 2010).

Based on the seven species reported in official statistics (MIPAAF, 2014), CPUE values recorded in this present study resulted to be higher than those previously reported for the region (33.2 and $53 \mathrm{~kg}$ per vessel per day, respectively). This discrepancy could be related to different periods of time, as the official statistics referred to 2012, but could also reflect the previously mentioned difficulties in monitoring actual catches. This has been partially confirmed by comparing collected data with those from the Chioggia fish market, the most important in the Northern Adriatic Sea. Considering the eight most abundant species (representing at least $2 \%$ of the total catch), in the two different scenarios for fishing effort, only cuttlefish, common sole, and brill showed higher values at the fish market. This again confirms the poor reliability of fish market data from the area.

All of the fishing gear analyses confirmed a very low discard incidence (in terms of biomass), which were even lower than those reported for other Adriatic areas (Fabi and Grati, 2005). This situation is quite similar to that described for the Croatian coast, where the by-catch of commercial species is often utilized by fishermen for personal consumption or as bait (Matić-Skoko et al., 2011).

The PPR (Pauly and Christensen, 1995) and L-index (Libralato et al., 2008) are two indicators that have been proposed to assess the ecological footprint of fishing activities. For PPR, the results that we obtained were slightly higher than the mean values for the Mediterranean and Italian seas, which were $15 \%$ and $9 \%$, respectively (Sherman and Hempel, 2008; deLeo et al., 2014). Accordingly, the L-index showed values within the sustainable fishing range. However, increased fishing efforts and/or reduced primary production scenarios highlight the importance of artisanal fisheries in the area, reflecting increased PPR (also reaching 20\%) and reduced sustainability (with a probability reduced to less than $40 \%$ ). These two scenarios can be considered to be realistic because they are based on very recently measured trends. Indeed, the ban of trawling activities inside the three miles area is now leading to the reconversion of small trawlers towards artisanal fishing (Pranovi et al., 2015), although a recent study suggested a tendency towards water oligotrophy of the Northern Adriatic Sea (Giani et al., 2012). The analysis preformed at the level of single fishing gear revealed that the most 'impacting' gear resulted the be the pot and the gillnet, in terms of PPR and Lindex/psust, respectively. All this could partially be useful in addressing the management strategies, possibly promoting the use of less impacting gear, namely trammel net and basket trap. However, it is worthy to note that the artisanal fisheries resulted to be a dynamic combination of different fishing gear, according to the target species seasonality, making difficult to force the use of one fishing gear despite the others.

\section{Conclusions}

Artisanal fisheries along the West coast of the Northern Adriatic Sea exhibit features similar to those recorded in many other European areas, such as the large number of exploited species and polyvalence. Nevertheless, it also showed a high potential vulnerability because of the species dependence and catch composition in terms of thermal affinity groups. Finally, our analyses showed artisanal fishing to be a sustainable practice, but it also highlights how small modifications both in the fleet structure and environmental conditions could drive the situation towards unsustainability in the future (see also Whitmarsh et al., 2003).

Considering our findings together, if the present levels of artisanal fishing remain along with current levels of hydraulic dredging, and remain the sole fishing activities within the threemile area, a real management strategy will be required. Such a strategy must achieve the following two goals: to reduce conflicts between the two industries for fishing grounds, as both prefer the shallowest zones, and to avoid uncontrolled increases in fishing effort, which could overcome the positive effects of the trawling ban if unchecked.

\section{Appendix A. Supplementary data}

Supplementary data related to this article can be found at http:// dx.doi.org/10.1016/j.ocecoaman.2016.01.004.

\section{References}

AdriaMed, 2005. Adriatic Sea Small-scale Fisheries. AdriaMed Technical Documents $15,184$.

Behrenfeld, M.J., Falkowski, P.G., 1997. Photosynthetic rates derived from satellitebased chlorophyll concentration. Limnol. Oceanogr. 42, 1-20.

Ben Rais Lasram, F., Guilhaumon, F., Albouy, C., Somot, S., Thuiller, W., Mouillot, D., 2010. The Mediterranean Sea as a "cul-de-sac" for endemic fishes facing climate change. Glob. Chang. Biol. 16, 3233-3245.

Battaglia, P., Romeo, T., Consoli, P., Scotti, G., Andaloro, F., 2010. Characterization of the artisanal fishery and its socio-economic aspects in the central Mediterranean Sea (Aeolian Islands, Italy). Fish. Res. 102, 87-97.

Colloca, F., Crespi, V., Cerasi, S., Coppola, S.R., 2004. Structure and evolution of the artisanal fishery in a southern Italian coastal area. Fish. Res. 69, 359-369.

de Leo, F., Miglietta, P., Pavlinović, S., 2014. Marine ecological footprint of Italian Mediterranean fisheries. Sustainability 6, 7482-7495.

De Mauro, M., Fabi, G., Grati, F., Polidori, P., Scarcella, G., 2007. Small-scale fishery in the Northern Adriatic Sea. Rapp. Comm. Int. Mer. Medit. 38, 454

Fabi, G., Grati, F., 2005. Small-scale fisheries in the maritime department of Ancona (Central Northern Adriatic Sea). AdriaMed Technical Documents 15, 85-97.

FAO, 2005. Increasing the Contribution of Small-scale Fisheries to Poverty Alleviation and Food Security. In: FAO Technical Guidelines for Responsible Fisheries, 10. FAO, Rome, p. 79.

Farrugio, H., Oliver, P., Biagi, F., 1993. An overview of the history, knowledge, recent and future research trends in Mediterranean fisheries. Sci. Mar. 57, 105-119.

Forcada, A., Valle, C., Sánchez-Lizaso, J.L., Bayle-Sempere, J.T., Corsi, F., 2010. Structure and spatio-temporal dynamics of artisanal fisheries around a Mediterranean marine protected area. ICES J. Mar. Sci. 67, 191-203.

Fortibuoni, T., Aldighieri, F., Giovanardi, O., Pranovi, F., Zucchetta, M., 2015. Climate impact on Italian fisheries (Mediterranean Sea). Reg. Environ. Change 15, 931-937.

Garcia, S.M., Allison, E.H., Andrew, N., Béné, C., Bianchi, G., De Graaf, G., Kalikoski, D., Mahon, R.L., Orensanz, L., 2008. Towards Integrated Assessment and Advice in Small-scale Fisheries: Principles and Processes. In: FAO Fisheries and Aquaculture Technical Paper, 515.

García-Rodríguez, M., Fernández Á.M., Esteban A., 2006. Characterisation, analysis and catch rates of the small-scale fisheries of the Alicante Gulf (SE Spain) over a 10 years time series. Fish. Res. 77, 226-238.

Giani, M., Djakovac, T., Degobbis, D., Cozzi, S., Solidoro, C., Fonda Umani, S., 2012. Recent changes in the marine ecosystems of the northern Adriatic Sea. Estuar. Coast. Shelf Sci. 115, 1-13. 
Guyader, O., Berthou, P., Koustikopoulos, C., Alban, F., Demaneche, S., Gaspar, M., Eschbaum, R., Fahy, E., Tully, O., Reynal, L., Curtil, O., Frangoudes, K., Maynou, F. 2013. Small-Scale fisheries in Europe: a comparative analysis based on a selection of case studies. Fish. Res. 140, 1-13.

Lehtonen, R., ad Pahkinen, E., 2004. Practical Methods for Design and Analysis of Complex Surveys, 2nd edn. John Wiley \& Sons Ltd, Chichester, West Sussex, p. 349.

Libralato, S., Coll, M., Tudela, S., Palomera, I., Pranovi, F., 2008. Quantifying ecosystem overfishing: theoretical development and application of a new index of fisheries' impact on marine trophic webs. Mar. Ecol. Progr. Ser. 355, 107-129.

Libralato, S., Caccin, A., Pranovi, F., 2015. Modelling species invasions using thermal and trophic niche dynamics under climate change. Front. Mar. Sci. http:// dx.doi.org/10.3389/fmars.2015.00029.

Matić-Skoko, S., Stagliciić, N., Pallaoro, A., Kraljević, M., Dulĉić, J., Tutman, P., Dragicevević, B., 2011. Effectiveness of conventional management in Mediterranean type artisanal fisheries. Estuar. Coast. Shelf Sci. 91, 314-324.

MIPAAF, 2014. Rapporto annuale 2012. Strutture produttive, andamento pesca. Ministero delle Politiche Agricole. Alimentari e Forestali, Roma.

Pauly, D., Christensen, V., 1995. Primary production required to sustain global fisheries. Nature 374, 255-257.

Pranovi, F., Caccin, A., Franzoi, P., Malavasi, S., Zucchetta, M., Torricelli, P., 2013. Vulnerability of artisanal fisheries to climate change in the Venice lagoon. J. Fish Biol. 83, 847-863.
Pranovi, F., Libralato, S., Zucchetta, M., Link, J.S., 2014. Biomass accumulation across trophic level: analysis of landings for the Mediterranean Sea. Mar. Ecol. Progr. Ser. 512, 201-216.

Pranovi, F., Anelli Monti, M., Caccin, A., Brigolin, D., Zucchetta, M., 2015. Permanen trawl fishery closures in the Mediterranean Sea: an effective management strategy? Mar. Pol. 60, 272-279.

Shao, J., Tu, D., 1996. The Jackknife and Bootstrap. Corr. 2nd printing. Springer, New York, p. 516.

Sherman, K. Hempel, G., 2008. The UNEP Large Marine Ecosystem Report: Perspective on Changing Conditions in LMEs of the World's Regional Seas; UNEP Regional Seas Reports and Studies No. 182. United Nations Environmen Programme, Nairobi, Kenya.

Stergiou, K.I., Moutopoulos, D.K., Soriguer, M.C. Puente, E., Lino, P.G., Zabala, C., Monteiro, P., Errazkin, L.A., Erzini, K., 2006. Trammel net catch species composition, catch rates and metiers in southern European waters: a multivariate approach. Fish. Res. 79, 170-182.

Tzanatos, E., Dimitriou, E., Katselis, G., Georgiadis, M., Koutsikopoulos, C., 2005. Composition, temporal dynamics and regional characteristics of small-scale fisheriesin Greece. Fish. Res. 73, 147-158.

Whitmarsh, D., Pipitone, C., Badalamenti, F., D'Anna, G., 2003. The economic sustainability of artisanal fisheries: the case of the trawl ban in the Gulf of Castellammare, NW Sicily. Mar. Pol. 27, 489-497. 